\title{
Cultured Lung Fibroblasts Isolated from Patients with Idiopathic Pulmonary Fibrosis Have a Diminished Capacity to Synthesize Prostaglandin $\mathrm{E}_{2}$ and to Express Cyclooxygenase-2
}

\author{
Jerome Wilborn, ${ }^{\star}$ Leslie J. Crofford, ${ }^{\star}$ Marie D. Burdick, ${ }^{*}$ Steven L. Kunkel, ${ }^{\mathbf{5}}$ Robert M. Strieter, ${ }^{*}$ and Marc Peters-Golden ${ }^{\star}$ \\ Divisions of *Pulmonary and Critical Care Medicine and ${ }^{\ddagger}$ Rheumatology, Department of Internal Medicine, and ${ }^{\S}$ Department of \\ Pathology, University of Michigan and Department of Veterans Affairs Medical Centers, Ann Arbor, Michigan 48109
}

\begin{abstract}
Prostaglandin $\mathrm{E}_{2}\left(\mathrm{PGE}_{2}\right)$ inhibits fibroblast proliferation and collagen synthesis. In this study, we compared lung fibroblasts isolated from patients with idiopathic pulmonary fibrosis (F-IPF) and from patients undergoing resectional surgery for lung cancer ( $F$-nl) with respect to their capacity for $\mathrm{PGE}_{2}$ synthesis and their expression and regulation of cyclooxygenase (COX) proteins. Basal COX activity, assessed by quantitating immunoreactive $\mathrm{PGE}_{2}$ synthesized from arachidonic acid, was twofold less $(P<0.05)$ in $F$ IPF than F-nl. In F-nl, incubation with the agonists PMA, LPS, or IL-1 increased COX activity and protein expression of the inducible form of $\mathrm{COX}, \mathrm{COX}-2$, and these responses were inhibited by coincubation with dexamethasone. By contrast, F-IPF failed to demonstrate increases in COX2 protein expression or COX activity in response to these agonists. Under conditions of maximal induction, $\mathrm{COX}$ activity in F-IPF was sixfold less than that in F-nl $(P<0.05)$. Our data indicate that F-IPF have a striking defect in their capacity to synthesize the antiinflammatory and antifibrogenic molecule $\mathrm{PGE}_{2}$, apparently because of a diminished induction of COX-2 protein. This reduction in the endogenous capacity of F-IPF to down-regulate their function via $\mathrm{PGE}_{2}$ may contribute to the inflammatory and fibrogenic response in IPF. Moreover, we believe that this represents the first description of a defect in COX-2 expression in association with a human disease. (J. Clin. Invest. 1995. 95:18611868.) Key words: arachidonic acid - lipopolysaccharide • eicosanoids • interleukin-1 $\beta$ - prostaglandin $\mathbf{H}$ synthase
\end{abstract}

\section{Introduction}

Idiopathic pulmonary fibrosis (IPF) ${ }^{1}$ is the most common of the interstitial lung diseases, a group of disorders characterized

\footnotetext{
Address correspondence to Marc Peters-Golden, M.D., Division of Pulmonary and Critical Care Medicine, 3916 Taubman Center, University of Michigan Medical Center, Ann Arbor, MI 48109-0360. Phone: 313936-2612; FAX: 313-764-4556.

Received for publication 29 July 1994 and in revised form 24 October 1994.

1. Abbreviations used in this paper: COX, cyclooxygenase (PGH synthase); EIA, enzyme-linked immunoassay; F-IPF, lung fibroblasts isolated from patients with IPF; F-nl, normal lung fibroblasts; IPF, idiopathic pulmonary fibrosis; PLA $A_{2}$, phospholipase $A_{2} ; R T$, reverse transcriptase.
}

The Journal of Clinical Investigation, Inc.

Volume 95, April 1995, 1861-1868 by inflammatory injury and fibrosis of the lung parenchyma. Fibrosis is generally considered to be an irreversible finding and is the hallmark of IPF. This fibrotic component of IPF is characterized by both a striking increase in the number of fibroblasts and the deposition of fibroblast-derived extracellular matrix proteins, especially collagen (1). Fibroblast proliferation and collagen synthesis are therefore of central importance in IPF, and the modulation of these processes by effector molecules such as cytokines $(2-4)$, growth factors $(5,6)$, and eicosanoids (7) is of great interest.

Among those factors that downregulate fibroblast function, prostaglandin $\mathrm{E}_{2}\left(\mathrm{PGE}_{2}\right)$ has been the most extensively studied. This lipid mediator has been shown to decrease fibroblast proliferation $(8,9)$ and reduce collagen levels by inhibiting its synthesis $(10,11)$ and promoting its degradation (12). Since $\mathrm{PGE}_{2}$ is a major eicosanoid product of fibroblasts $(13-15)$, it is plausible to speculate that this molecule might regulate fibroblast function in an autocrine fashion.

The initial steps in the metabolism of arachidonic acid (AA) to $\mathrm{PGE}_{2}$ and other prostaglandins (PGs) are catalyzed by the enzyme PGH synthase, or cyclooxygenase (COX) (16). Two distinct isozymes of COX, COX-1 and COX-2, have been identified. Whereas COX-1 is constitutively expressed in many tissues (17), COX-2 has been shown to be inducible by a variety of stimuli, such as PMA, IL-1, and LPS, in a number of cell types (18-21). In Swiss 3T3 fibroblasts, for example, increases in COX activity in response to IL-1 and PMA have been shown to correlate with increases in COX-2 protein (21).

We undertook this study to determine whether the eicosanoid profile and the regulation of PG synthesis in fibroblasts isolated from patients with IPF (F-IPF) differed from those observed in normal human pulmonary fibroblasts (F-nl). Our data indicate that, although F-nl and F-IPF had identical eicosanoid profiles, F-IPF exhibited significantly less COX activity at baseline than F-nl. Moreover, when cells from the two populations were stimulated with IL-1, PMA, or LPS, F-nl responded by increasing their $\mathrm{PGE}_{2}$ production over baseline, but F-IPF did not. In cells from both groups, these metabolic responses correlated with their capacities to up-regulate the expression of COX-2 protein.

\section{Methods}

Patient populations. The IPF study group consisted of nine previously untreated patients from the University of Michigan Specialized Center of Research in Interstitial Lung Disease project. These patients displayed radiographic and clinical findings consistent with IPF; pathologic confirmation of IPF was made by open lung biopsy. There were three males and six females, with a mean \pm SEM age of 55.2 \pm 14.9 yr (range 28$69 \mathrm{yr}$ ). All patients were current nonsmokers. The degrees of inflammation and fibrosis in each of three separate biopsy specimens obtained from different bronchopulmonary segments were scored by a pathologist 
using published criteria (22), and the mean inflammation and fibrosis scores from the three specimens were calculated for each patient. The study group from which F-nl were isolated consisted of eight patients undergoing pulmonary resection for bronchogenic carcinoma. There were five males and three females, with a mean age of $54 \pm 15.1 \mathrm{yr}$ (range 39-72 yr). One was a current smoker, five were former smokers (ceased at least 2 mo before surgery), and two were patients who never smoked. F-nl were isolated from areas of lung parenchyma that were considered histopathologically normal. The experimental protocol was approved by the University of Michigan Medical Center Institutional Review Board for Approval of Research Involving Human Subjects. The number of patients from whom cells were taken for each experiment is as indicated in the text and figure legends.

Isolation and culture of pulmonary fibroblasts. Fibroblasts were isolated from open lung tissue biopsy specimens using methods previously described (23). Briefly, lung tissue samples were isolated under sterile conditions, and $1-\mathrm{mm}^{3}$ fragments from each of the three sampled segments were pooled and placed in DME (Gibco Laboratories, Grand Island, NY) with 10\% LPS-free FCS (HyClone Laboratories, Inc., Logan, UT). Fibroblasts proliferating from these specimens were grown to $80 \%$ confluence and serially passed in the same medium. At the fifth passage, fibroblasts were seeded into 96 -well plates $\left(0.25 \times 10^{5}\right.$ cells per well ) for metabolic studies, 60 -mm dishes $\left(4 \times 10^{5}\right.$ per dish $)$ for immunoblot analysis, and $175-\mathrm{mm}$ flasks $\left(10^{7}\right.$ per flask) for RNA analysis. Confluent cells were washed and rendered quiescent by culturing in serum- and LPS-free DME. They were then cultured for 1-72 $\mathrm{h}$ in the presence or absence of LPS from Escherichia coli (serotype O111:B4, Sigma Chemical Co., St. Louis, MO) (100 ng/ml), human recombinant IL-1 $\beta$ (Collaborative Biomedical Products, Bedford, MA) $(2.5 \mathrm{ng} / \mathrm{ml})$, PMA (Sigma Chemical Co.) $(50 \mathrm{nM})$, and/or dexamethasone (Sigma Chemical Co.) $(1 \mu \mathrm{M})$ before harvesting. Cells were cultured at $37^{\circ} \mathrm{C}$ in a humidified atmosphere of $5 \% \mathrm{CO}_{2}$ in air.

Separation of eicosanoids. Cellular lipids of fibroblasts cultured in 96-well plates were prelabeled by including $1 \mu \mathrm{Ci}$ of $\left[{ }^{3} \mathrm{H}\right] \mathrm{AA}$ (sp act 76-100 Ci/mmol; Du Pont-New England Nuclear, Boston, MA) in the medium for $16 \mathrm{~h}$. Unincorporated label was removed by washing cells with DME, and cells were then incubated for $30 \mathrm{~min}$ with ionophore A23187 (5 $\mu \mathrm{M})$. Radiolabeled free AA and its eicosanoid metabolites were extracted from the medium, and pooled lipid extracts from four wells were subjected to reverse-phase HPLC as previously described (24). Radioactivity was determined on-line using a Radiomatic Flo-One Beta detector (Packard Instrument Co., Downers Grove, IL).

Determination of $P G E_{2}$ accumulation. After a 16- or 72-h incubation in serum-free medium, cumulative $\mathrm{PGE}_{2}$ synthesis from endogenous $\mathrm{AA}$ was determined by assaying supernatants with an enzyme-linked immunoassay (EIA; Cayman Chemical, Ann Arbor, MI) according to the manufacturer's instructions.

Determination of COX and PGE isomerase activities. $\mathrm{PGE}_{2}$ accumulation reflects the actions of both phospholipase $\mathrm{A}_{2}\left(\mathrm{PLA}_{2}\right)$ and COX. To bypass $\mathrm{PLA}_{2}$ and therefore estimate maximal COX metabolic capacity, cells were incubated as already outlined for 1,16 , or $72 \mathrm{~h}$, washed, and incubated for $30 \mathrm{~min}$ in DME containing exogenous AA (10 $\mu \mathrm{M})$. $\mathrm{PGE}_{2}$ formation in the supernatant was then quantitated by EIA. Preliminary experiments indicated that this dose of AA was saturating, as indicated by maximal $\mathrm{PGE}_{2}$ synthesis (data not shown). In a similar fashion, PGE isomerase activity was determined after a 15-min incubation with exogenous $\mathrm{PGH}_{2}$ and subsequent quantitation of $\mathrm{PGE}_{2}$. All assays were performed in duplicate, and activities were expressed as $\mathrm{PGE}_{2}$ formed in nanograms per microgram of cellular protein. Protein concentration was determined by a microtiter plate modification (Pierce Biochemical, Rockford, IL) of the Bradford method (25) using BSA as a standard.

Preparation of crude cell lysates. F-nl or F-IPF were harvested from $60-\mathrm{mm}$ plates by scraping with a rubber policeman in $250 \mu \mathrm{l}$ of icecold homogenizing buffer ( $50 \mathrm{mM}$ potassium phosphate, $0.1 \mathrm{M} \mathrm{NaCl}$, $2 \mathrm{mM}$ EDTA, $1 \mathrm{mM}$ DTT, $0.5 \mathrm{mM}$ PMSF, $60 \mu \mathrm{g} / \mathrm{ml}$ soybean trypsin inhibitor, $\mathrm{pH}$ 7.1). The cell suspension was sonicated on ice using a model 250 sonifier (Branson Ultrasonics Corp., Danbury, CT) at a power level of $1,20 \%$ duty cycle for $1.5 \mathrm{~min}$.

Immunoblot analysis. Aliquots of F-nl and F-IPF lysates containing $20 \mu \mathrm{g}$ of total protein were combined 1:1 ( $\mathrm{vol} / \mathrm{vol})$ with SDS sample buffer ( $125 \mathrm{mM}$ Tris- $\mathrm{HCl}, 4 \%$ SDS, $20 \%$ glycerol, $10 \% \beta$-mercaptoethanol, $\mathrm{pH}$ 6.8) and immediately boiled for $3 \mathrm{~min}$. They were then subjected to SDS-PAGE on $10 \%$ acrylamide gels overlaid with a $5 \%$ stacking gel by the method of Laemmli (26). High molecular weight rainbow markers (Amersham Corp., Arlington Heights, IL) and COX-1 and COX-2 standards were run in parallel in each gel. The COX-1 standard (Oxford Biomedical Research, Inc., Oxford, MI) was purified from sheep seminal vesicle, and the COX-2 standard (generously provided by D. DeWitt, Michigan State University, East Lansing, MI) consisted of microsomes from cos cells transfected with the cDNA for murine COX-2 (27). Proteins were transferred to nitrocellulose (Bio Rad Laboratories, Richmond, CA) using a Trans-Blot Cell (Hoefer Scientific Instruments, San Francisco, CA), and membranes were blocked for 1 $\mathrm{h}$ with $10 \%$ nonfat dry milk reconstituted with $0.1 \%$ Tween in Trisbuffered saline ( $50 \mathrm{mM}$ Tris- $\mathrm{HCl}, 150 \mathrm{mM} \mathrm{NaCl}, \mathrm{pH}$ 7.5) (TBST). The membranes were washed for $5 \mathrm{~min}$ in TBST and then incubated for $1 \mathrm{~h}$ with either anti-COX-1 antiserum (1:5,000 dilution) or antiCOX-2 antiserum (1:300 dilution). The former is a rabbit polyclonal antibody raised against sheep seminal vesicle $\operatorname{COX}(28)$, and the latter is a rabbit polyclonal antibody raised against a 17 -amino acid peptide derived from the murine COX-2 sequence that is not present in COX1 (29). After another 15-min wash in TBST, the membrane was incubated for $1 \mathrm{~h}$ with horseradish peroxidase-conjugated goat anti-rabbit IgG secondary antibody (1:10,000 for COX-1 and 1:5,000 for COX-2) followed by three 5-min washes in $0.3 \%$ TBST and three 5-min washes in TBST. Detection was accomplished using the ECL enhanced chemiluminescence method (Amersham Corp.) according to the manufacturer's directions. Multiple exposures were obtained for each membrane, and the densities of bands corresponding to $\mathrm{COX}-1$ and $\mathrm{COX}-2$ were quantitated by video densitometry of appropriately exposed autoradiographs using image analysis software from Scion (Frederick, MD). To compare the steady-state basal levels of COX-1 and COX-2 among all the F-nl and F-IPF patients, all samples were loaded in a random fashion on the same gel and processed in parallel; band densities, expressed in arbitrary densitometric units, were determined. To analyze the effects of agonists on COX protein levels, different experimental samples from a given patient were loaded on the same gel and processed in parallel, and the densities of bands from agonist-treated samples were expressed as a percentage of that from the control (unstimulated) sample.

RNA preparation and analysis. Total RNA was prepared from cultured fibroblasts by the Tri-Reagent method (Molecular Research Center, Inc., Cincinnati, OH). For PCR analysis of RNA, cDNA was prepared by reverse transcription of $1 \mu \mathrm{g}$ of each RNA sample in a 50- $\mu$ l reaction containing $50 \mathrm{mM}$ Tris- $\mathrm{HCl}, \mathrm{pH} 8.3,40 \mathrm{mM} \mathrm{KCl}, 6 \mathrm{mM}$ $\mathrm{MgCl}_{2}, 1 \mathrm{mM}$ DTT, $0.4 \mathrm{mM}$ dNTPs, $2 \mu \mathrm{M}$ random hexamer primers (Perkin Elmer-Cetus, Norwalk, CT), $0.2 \mathrm{U} / \mu \mathrm{l}$ RNase inhibitor (Perkin Elmer-Cetus), and $8 \mathrm{U} / \mu \mathrm{l}$ Moloney-murine leukemia virus reverse transcriptase (RT) (Life Technologies, Inc., Bethesda, MD). The reaction mixtures were incubated at room temperature for $10 \mathrm{~min}$, at $42^{\circ} \mathrm{C}$ for $30 \mathrm{~min}$, and at $95^{\circ} \mathrm{C}$ for $5 \mathrm{~min}$. The cDNAs were then diluted to $100 \mu \mathrm{l}$, and the same cDNA mixtures were used in all PCRs. PCRs performed in a $50-\mu \mathrm{l}$ reaction volume containing $5 \mu \mathrm{l}$ of each cDNA, $10 \mathrm{mM}$ Tris$\mathrm{HCl}, \mathrm{pH} 8.3,50 \mathrm{mM} \mathrm{KCl}, 25 \mathrm{mM} \mathrm{MgCl}_{2}, 50 \mu \mathrm{M}$ each of dATP, dCTP, dGTP, and dTTP, $5 \mu$ l of $\left[\alpha{ }^{32} \mathrm{P}\right] \mathrm{dCTP}(3,000 \mathrm{Ci} / \mathrm{mmol}$; Du PontNew England Nuclear), and $0.05 \mu \mathrm{l}$ of Taq polymerase (Perkin ElmerCetus). The primers used were (a) human COX-1, sense 5'-TGC CCA GCT CCT GGC CCG CCG CTT- ${ }^{\prime}$ ' and antisense 5'-GTG CAT CAA CAC AGG CGC CTC TTC-3'; $(b)$ human COX-2, sense 5'-TTC AAA TGA GAT TGT GGG AAA ATT GCT- ${ }^{\prime}$ ' and antisense 5'-AGA TCA TCT CTG CCT GAG TAT CTT-3'; and (c) G3PDH, sense 5' -CCA CCC ATG GCA AAT TCC ATG GCA-3' and antisense 5'-TCT AGA CGG CAG GTC AGG TCC ACC-3'. All primer pairs amplified a fragment that crossed an intron, thereby distinguishing cDNA from genomic DNA by the size of the expected fragment after amplification. 


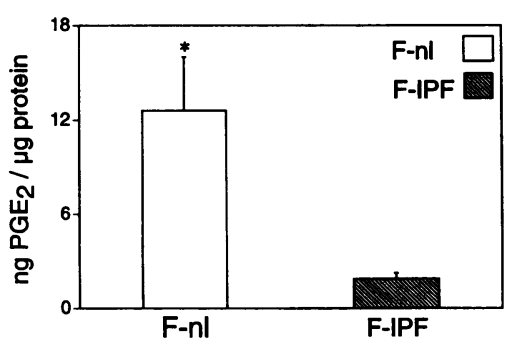

Figure 1. $\mathrm{PGE}_{2}$ accumulation over $16 \mathrm{~h}$ in F-nl and F-IPF. Both F-nl and F-IPF were grown to $80 \%$ confluence. They were then incubated for $16 \mathrm{~h}$ in serum-free medium. Aliquots of the supernatants were used to quantitate $\mathrm{PGE}_{2}$ by EIA. Results are expressed in nanograms of $\mathrm{PGE}_{2}$ per microgram of total cell protein per well. Each bar represents mean \pm SEM from $n=3 .{ }^{*} P<0.05$ versus corresponding F-nl value by unpaired $t$ test.

The conditions for amplification were as follows: $\mathrm{COX}-2,95^{\circ} \mathrm{C}$ for 2 $\min$ for $1 \mathrm{cycle}, 95^{\circ} \mathrm{C}$ for $1 \mathrm{~min}, 60^{\circ} \mathrm{C}$ for $1 \mathrm{~min}, 72^{\circ} \mathrm{C}$ for $1 \mathrm{~min}$ for 35 cycles, and $72^{\circ} \mathrm{C}$ for $7 \mathrm{~min}$ for 1 cycle; and COX-1 and G3PDH, $95^{\circ} \mathrm{C}$ for $1 \mathrm{~min}, 60^{\circ} \mathrm{C}$ for $1 \mathrm{~min}$, and $72^{\circ} \mathrm{C}$ for $1 \mathrm{~min}$ for 25 cycles. Both cycle programs were preceded by $2 \mathrm{~min}$ at the stated denaturation temperature and followed by $7 \mathrm{~min}$ at $72^{\circ} \mathrm{C}$. Cycle curve studies between 25 and 35 cycles confirmed that, for the amounts of cDNA being amplified, the reactions had not reached the plateau of the amplification curve for any primer pair. Negative controls performed with no RNA added to the reverse transcription reaction or no RT yielded no detectable fragments with either primer pair.

Data analysis. Where applicable, data are expressed as mean \pm SEM. Paired or unpaired Student's $t$ tests were used to analyze differences in enzyme activity or steady-state COX protein levels. Linear correlation analysis was used to assess the correlation between $\mathrm{PGE}_{2}$ synthetic capacity and fibrosis scores. Significance was inferred from a $P$ value $<0.05$.

\section{Results}

Constitutive $P G E_{2}$ accumulation in cultures of F-nl and F-IPF. To assess the capacity of F-nl and F-IPF to produce $\mathrm{PGE}_{2}$ in the absence of an agonist, equal numbers of cells were cultured in serum- and LPS-free DMEM for $16 \mathrm{~h}$, and $\mathrm{PGE}_{2}$ released into the medium was quantitated. F-IPF produced 6.5 -fold less immunoreactive $\mathrm{PGE}_{2}$ per $\mu \mathrm{g}$ of protein than did F-nl ( $P$ $<0.05, n=3$ for F-nl and F-IPF) (Fig. 1). The protein content did not differ significantly between F-nl and F-IPF $(\sim 130 \mu \mathrm{g}$ of crude lysate protein per $60-\mathrm{mm}$ dish at $80 \%$ confluence for both F-nl and F-IPF).

Eicosanoid profile in $F-n l$ and $F-I P F$. $\mathrm{PGE}_{2}$ synthesis from endogenous AA reflects the sequential activities of PLA $\mathrm{A}_{2}$ and COX. To determine whether the defect in F-IPF PGE P $_{2}$ synthesis reflected a defect in $\mathrm{PLA}_{2}$-dependent $\mathrm{AA}$ release, we assessed the release of radiolabeled products from prelabeled cells stimulated with A23187 for $30 \mathrm{~min}$. Completely separating free AA and all its metabolites by HPLC further permitted us to determine whether the two cell populations metabolized AA into different eicosanoid products and, in particular, whether there was a differential capacity for these cells to synthesize antiinflammatory PG and proinflammatory leukotrienes. As shown in the experiment depicted in Fig. 2, which is representative of a total of two independent experiments, both cell types produced a similar profile of eicosanoids upon stimulation, with $\mathrm{PGE}_{2}$ and free AA being the major products. Neither cell type produced any detectable products of the 5-, 12-, or 15-lipoxygenase pathways. These data clearly establish that F-IPF were capable of releasing endogenous $\mathrm{AA}$; however, the ratio of $\mathrm{PGE}_{2}$ to free

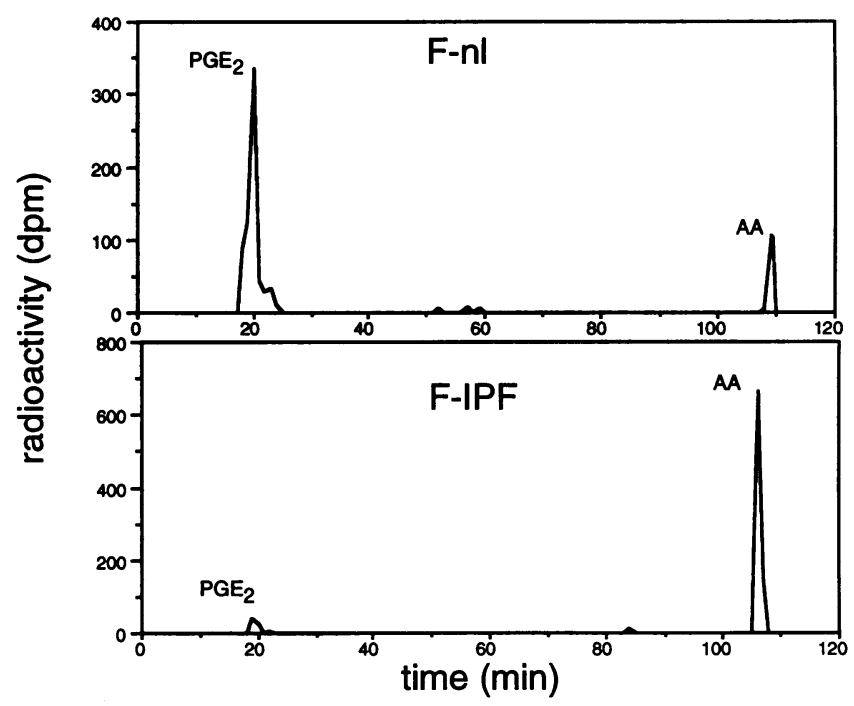

Figure 2. Radiolabeled eicosanoid profile of ionophore-stimulated F-nl and F-IPF. Cellular lipids of fibroblasts were prelabeled with [ $\left.{ }^{3} \mathrm{H}\right] \mathrm{AA}$ during a 16-h culture in 96-well plates. Unincorporated label was removed, and cells were washed and then incubated for $30 \mathrm{~min}$ with 5 $\mu \mathrm{M}$ A23187. Radiolabeled products in pooled extracts from four wells were separated by HPLC, and radioactivity was determined via on-line detection. Peaks of radioactivity were identified on the basis of comigration with authentic standards. Similar results were obtained in a separate experiment using another pair of F-nl and F-IPF.

AA was strikingly lower ( $\sim 18$-fold in the example shown in Fig. 2) in F-IPF than in F-nl. This indicates that the primary limitation in $\mathrm{PGE}_{2}$ synthesis was in utilization of released $\mathrm{AA}$ by the COX pathway of F-IPF.

COX activity in unstimulated $F-n l$ and F-IPF. To focus more directly on this apparent defect in COX metabolism, we added exogenous AA in order to bypass $\mathrm{PLA}_{2}$, thereby assessing maximal COX activity by quantitating $\mathrm{PGE}_{2}$ formation. Because both cell proliferation (30) and serum (31) can influence PG synthesis and COX activity, we studied cells at various time points up to $72 \mathrm{~h}$ after the removal of serum to ensure that any residual effects of serum had abated. There were no significant differences in COX activity over the 72-h culture period (i.e., at 1,16 , or $72 \mathrm{~h}$ ) for either fibroblast population (Fig. 3). Interestingly, COX activity was 2.5 -fold lower in FIPF as compared with F-nl $(P<0.05)$ at all time points studied (Fig. 3). All subsequent experiments were performed at $16 \mathrm{~h}$.

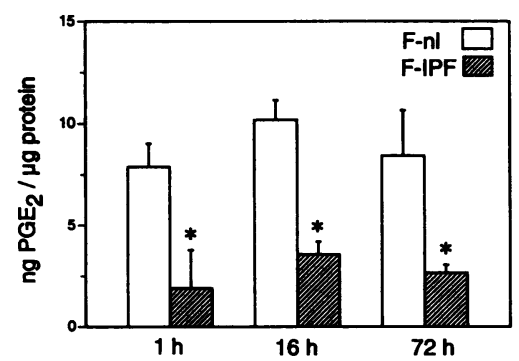

Figure 3. COX activity in F-nl and F-IPF. Subconfluent F-nl and F-IPF were cultured in serumfree medium for 1,16 , or $72 \mathrm{~h}$, washed, and then incubated with $10 \mu \mathrm{M}$ AA for $15 \mathrm{~min}$. Aliquots of the cell supernatants were used to quantitate $\mathrm{PGE}_{2}$ by EIA. Results are expressed in nanograms of $\mathrm{PGE}_{2}$ per microgram of total cell protein per well. Each bar represents mean \pm SEM from $n=4$. ${ }^{*} P<0.05$ versus corresponding F-nl value by unpaired $t$ test. 
A

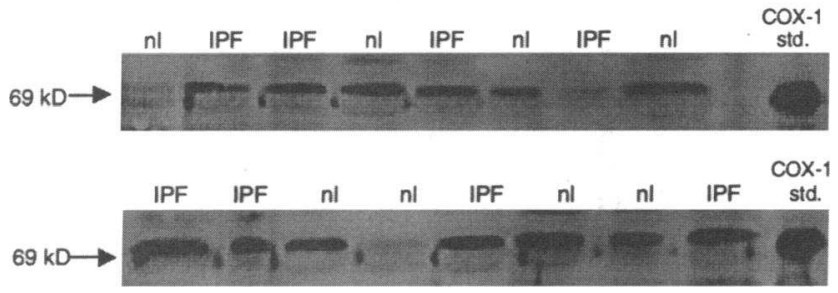

B

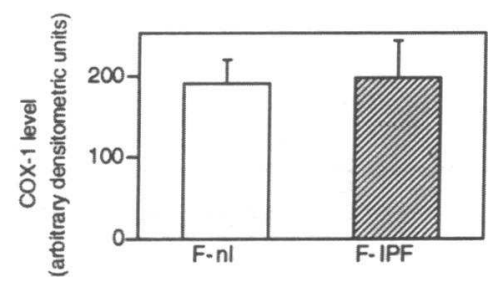

C

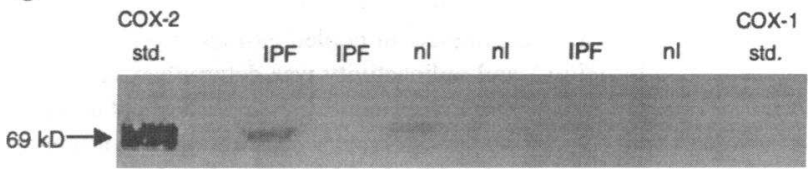

Figure 4. Immunoblot analysis of COX proteins in unstimulated F-nl and F-IPF. Cells were cultured for $16 \mathrm{~h}$ in serum-free medium and harvested for immunoblot analyses as described in Methods using 20 $\mu \mathrm{g}$ of crude lysate protein per lane. (A) Autoradiograph depicting COX1 expression in cells from eight $\mathrm{nl}$ and eight IPF patients. Migration of a molecular weight marker is indicated by the arrows. COX-1 standard was run in the right lanes. $(B)$ Densitometric analysis of COX-1 bands in F-nl and F-IPF from the above autoradiograph. Data are expressed as arbitrary densitometric units, and each bar represents mean \pm SEM. (C) Autoradiograph depicting COX-2 expression in cells from three $\mathrm{nl}$ and three IPF patients. Migration of a molecular weight marker is indicated by the arrow. A COX-1 standard was run in the right lane, and a COX-2 standard in the left.

The formation of $\mathrm{PGE}_{2}$ from $\mathrm{AA}$ requires the actions of not only COX, but also PGE isomerase. To exclude the possibility that differences in $\mathrm{PGE}_{2}$ synthesis were attributable to differences in PGE isomerase activity between the two cell populations, $\mathrm{PGE}_{2}$ formation from exogenously supplied $\mathrm{PGH}_{2}(5 \mu \mathrm{M})$ was determined. Both F-nl and F-IPF synthesized equally large amounts of $\mathrm{PGE}_{2}$ from exogenously supplied $\mathrm{PGH}_{2}$ (396 \pm 84.3 ng per $\mu \mathrm{g}$ of protein for $\mathrm{F}-\mathrm{nl}$ and $473 \pm 67.8 \mathrm{ng}$ per $\mu \mathrm{g}$ of protein for F-IPF) $(P>0.05, n=3)$. Moreover, this 40 -fold (in Fnl) to 100-fold (in F-IPF) greater capacity for production of $\mathrm{PGE}_{2}$ from exogenous $\mathrm{PGH}_{2}$ than from exogenous AA confirms that COX itself is the rate-limiting step within this metabolic pathway. Our finding that differences between F-nl and F-IPF in $\mathrm{PGE}_{2}$ production from exogenous $\mathrm{AA}$ were attributable to differences in the activity of COX itself was therefore expected.

Immunoblot analysis of $\mathrm{COX}$ proteins in unstimulated $f$ broblasts. The expression of COX-1 and COX-2 proteins was examined in F-nl and F-IPF cultured for $16 \mathrm{~h}$ in serum- and LPS-free medium. Crude lysates from both cell populations were subjected to immunoblot analysis using polyclonal antisera specific for COX-1 and COX-2. As shown in Fig. $4 A$, most

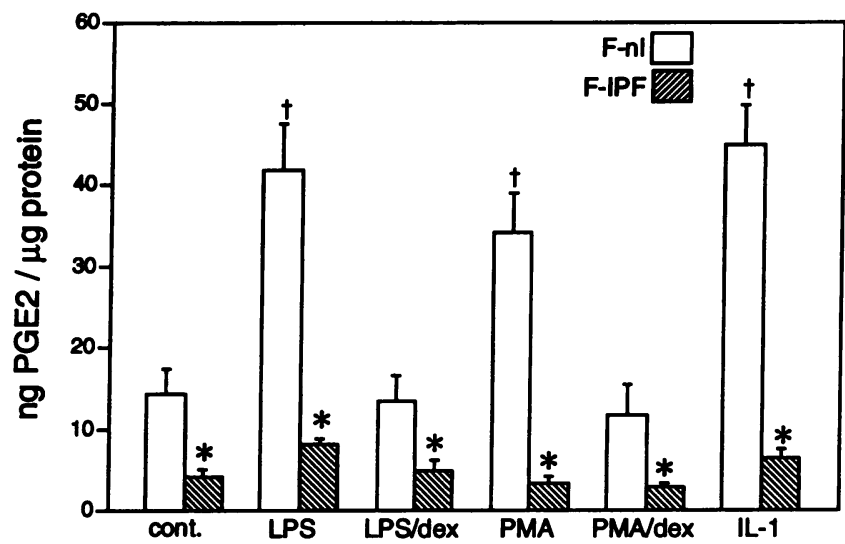

Figure 5. COX activity in stimulated F-nl and F-IPF. Cells were incubated for $16 \mathrm{~h}$ in the presence or absence (control; cont.) of $100 \mathrm{ng} /$ $\mathrm{ml} \mathrm{LPS} \mathrm{(} n=7$ for F-nl; $n=8$ for F-IPF), $50 \mathrm{nM}$ PMA ( $n=5$ for both F-nl and F-IPF), or $2.5 \mathrm{ng} / \mathrm{ml} \mathrm{IL-1} \beta$ ( $n=3$ for both F-nl and FIPF) and $1 \mu \mathrm{M}$ dexamethasone (dex). Cells were washed and then incubated with $10 \mu \mathrm{M}$ AA for $15 \mathrm{~min}$. Aliquots of the supernatants were used to quantitate $\mathrm{PGE}_{2}$ by EIA. Results are expressed in nanograms of $\mathrm{PGE}_{2}$ per microgram of total cell protein per well. Each bar represents mean \pm SEM. $* P<0.05$ versus corresponding F-nl value by unpaired $t$ test; ${ }^{\dagger} P<0.05$ versus unstimulated control value by paired $t$ test.

of the cell samples in both groups ( $n=8$ for each) expressed COX-1 in the unstimulated state. Densitometric analysis revealed that $\mathrm{COX}-1$ expression in the two populations was similar (Fig. $4 \mathrm{~B}$ ). This was an unexpected finding, given the 2.5fold lower COX activity in unstimulated F-IPF as compared with unstimulated F-nl, and led us to consider that differences in COX-2 expression might be responsible for this difference in COX activity in the basal state. We found, however, very low levels of basal COX-2 expression in both groups. After prolonged exposure of autoradiographs, COX-2 was detectable in some subjects, but no differences were apparent between the two populations (Fig. $4 \mathrm{C}$ ).

COX activity in stimulated fibroblasts. In view of the reduction in COX activity in F-IPF in the basal state, we next examined COX activity in stimulated cells from the two populations. Previous studies have shown that various agonists can induce COX-2 protein and that coincubation with the glucocorticoid dexamethasone can prevent this induction. Cells were therefore incubated for $16 \mathrm{~h}$ with medium alone or in the presence of LPS (100 ng/ml), PMA (50 nM), or IL-1 $\beta$ (2.5 ng/ml), after which $\mathrm{COX}$ activity was assessed by quantitating $\mathrm{PGE}_{2}$ formed from exogenous AA. As shown in Fig. 5, F-nl increased their activity approximately two- to threefold in response to stimulation with each of these three agonists. By contrast, F-IPF exhibited no increase in COX activity with any of the agonists. Thus, in the stimulated state the difference in maximal COX activity between F-nl and F-IPF was even more pronounced: F-IPF exhibited sixfold less maximal COX activity than did F-nl ( $P$ $<0.05$ for LPS, PMA, and IL-1 stimulation). As expected, dexamethasone prevented the agonist-induced increase in COX activity in F-nl. Since F-IPF exhibited no induction of COX2 , it was not surprising that these cells were unaffected by dexamethasone.

Immunoblot analysis of COX proteins in stimulated fibroblasts. We next examined the expression of COX proteins in 


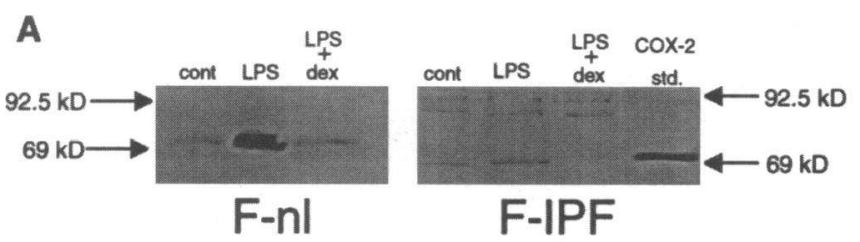

B

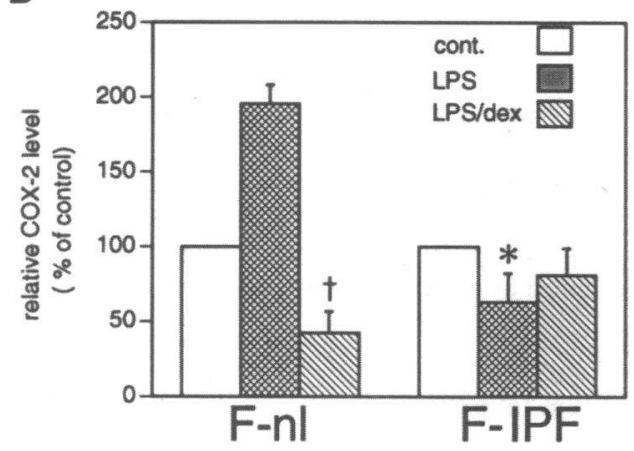

Figure 6. Immunoblot analysis of COX proteins in stimulated F-nl and F-IPF. Cells were incubated for $16 \mathrm{~h}$ in the absence (control; cont) or presence of $100 \mathrm{ng} / \mathrm{ml} \mathrm{LPS}, 2.5 \mathrm{ng} / \mathrm{ml} \mathrm{IL}$ $1 \beta$, or $1 \mu \mathrm{M}$ dexamethasone (dex). Crude lysate protein $(20 \mu \mathrm{g})$ was subjected to immunoblot analysis for COX-2 protein as described in Methods. $(A)$ Representative autoradiograph with migration of molecular weight markers indicated by the arrows. A COX-2 standard was run in the right lane. $(B)$ Densitometric analysis of COX-2 bands in F-nl and F-IPF incubated with medium alone (control; cont), LPS (LPS), and LPS plus dexamethasone (LPS/dex). Relative COX-2 levels are expressed as a percentage of control and represent mean \pm SEM from seven $\mathrm{nl}$ and eight IPF. ${ }^{*} P<0.05$ versus $\mathrm{F}-\mathrm{nl}$ by unpaired $t$ test; and ${ }^{\dagger} P<0.05$ versus LPS by paired $t$ test. ( $C$ ) Representative autoradiograph showing COX-2 induction in response to $2.5 \mathrm{ng} / \mathrm{ml}$ IL-1. cells stimulated with LPS, PMA, and IL-1. A representative autoradiograph shown in Fig. $6 \mathrm{~A}$ reveals that steady-state COX2 protein expression was increased by LPS in F-nl, and this induction was prevented by coincubation with dexamethasone. Such induction of COX-2 protein was not found in F-IPF. Densitometric analysis of COX-2 protein expression (Fig. $6 \mathrm{~B}$ ) indicates that in F-nl $(n=5)$, relative COX-2 expression increased approximately twofold $(P<0.05$ versus corresponding control value) in response to LPS and decreased below baseline control levels $(P<0.05)$ when cells were coincubated with LPS plus dexamethasone. By contrast, COX-2 was not induced in F-IPF in response to LPS $(n=5)$. Moreover, LPS-stimulated F-IPF expressed twofold less COX-2 than did LPS-stimulated F-nl. In a similar fashion, IL-1 induced COX-2 protein expression substantially over the control level in F-nl, but not in FIPF (Fig. $6 \mathrm{C}$ ). Similar induction of COX-2 in F-nl but not in F-IPF was observed with PMA treatment (data not shown). Agonist stimulation had no effect on COX-1 levels, and there was no significant difference in COX-1 expression between the two populations in the stimulated state (data not shown).

Expression of COX-2 mRNA in F-nl and F-IPF. To determine whether the defect responsible for the lack of COX-2 protein expression in F-IPF was pretranslational, we isolated total RNA from F-nl and F-IPF that had been stimulated with or without $100 \mathrm{ng} / \mathrm{ml}$ LPS. Fig. 7 demonstrates that cells from each individual patient examined were representative of the entire group with respect to their COX activity (top panel) and COX-2 protein expression (middle panel), in that F-nl (Fig. $7 A$ ) but not F-IPF (Fig. $7 B$ ) exhibited increases with LPS stimulation. RT-PCR analysis was performed on these F-nl and F-IPF in the basal and LPS-stimulated states. COX-2 mRNA in basal F-IPF was detectable only after 35 PCR cycles and failed to increase after incubation with LPS (Fig. $7 \mathrm{~B}$, bottom panel), mirroring the results obtained for COX-2 protein expression under the same treatment conditions (Fig. $7 \mathrm{~B}$, middle panel). Abundant mRNA was detected in F-nl at 35 cycles (Fig. 7A, bottom panel); in fact, COX-2 was detectable after only 25 cycles in F-nl. When normalized to G3PDH mRNA, a 2.8-fold increase in the COX-2 PCR fragment was observed in F-nl treated with LPS as compared with control, whereas there was no increase in COX-2 transcript after LPS treatment in FIPF. In sharp contrast to these striking differences in basal COX2 mRNA expression, basal COX-1 levels were similar in F-nl and F-IPF (data not shown).

Correlation between COX activity and fibrosis. To determine whether there was a correlation between COX activity and the degree of pulmonary fibrosis, COX activities in both basal and LPS-stimulated fibroblasts from patients with IPF were plotted against mean fibrosis scores. As shown in Fig. 8, a statistically significant inverse relationship existed between the PGE $_{2}$ synthetic capacity of LPS-stimulated F-IPF and fibrosis scores $(r=0.804)$. A similar correlation $(r=0.774)$ was noted for unstimulated F-IPF as well (data not shown).

\section{Discussion}

Fibroblasts have been studied extensively as target cells in fibrotic disorders, including IPF. Less is known about the possible role of fibroblasts as effector cells actively participating in the evolution of IPF. Because fibroblasts are known to synthesize $\mathrm{PGE}_{2}$, and this PG has the ability to downregulate fibroblast proliferation and collagen synthesis, we hypothesized that FIPF might exhibit a diminished capacity for $\mathrm{PGE}_{2}$ synthesis as compared with F-nl. This hypothesis was tested in primary cultures of fibroblasts isolated from lung biopsy specimens from patients with IPF and from nonfibrotic control patients undergoing resection for bronchogenic carcinoma. Our study yielded several major findings. ( $a$ ) F-IPF exhibited diminished capacity to synthesize $\mathrm{PGE}_{2}$ from endogenous $\mathrm{AA}$ in both basal and ionophore-stimulated conditions. (b) Similar reductions in 

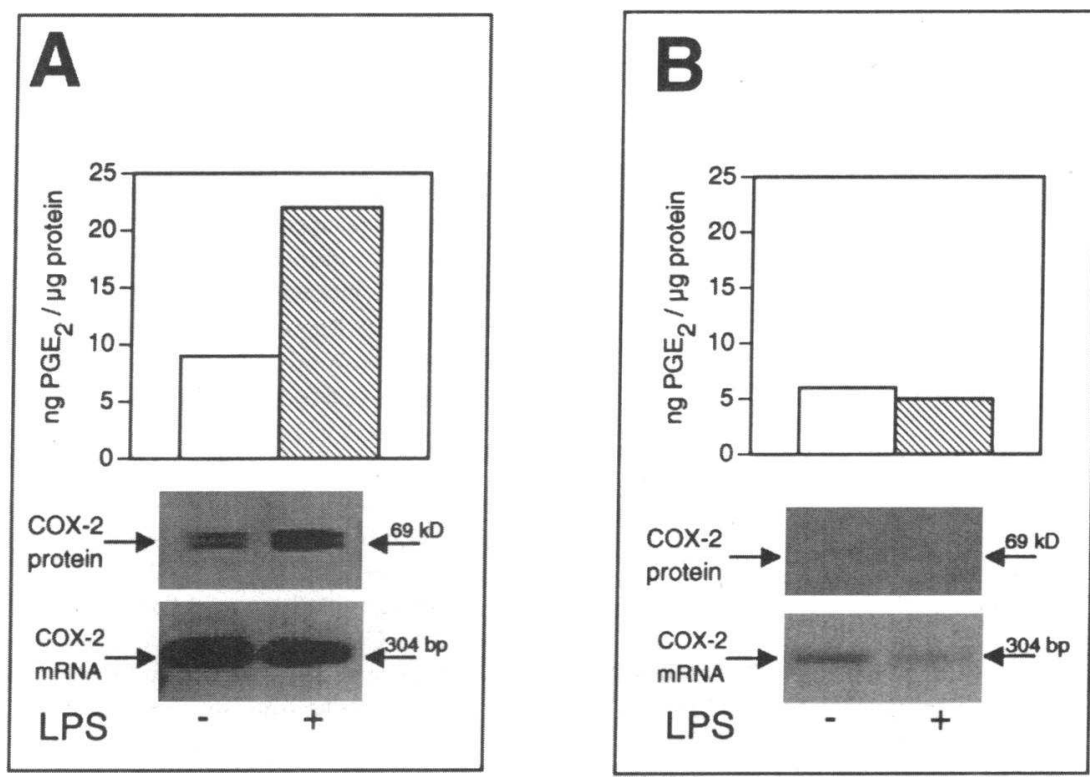

Figure 7. COX activity and expression of COX-2 protein and mRNA in F-nl and F-IPF. Cells from a patient without $(A)$ and with $(B)$ IPF were incubated for $16 \mathrm{~h}$ in the absence $(-)$ or presence $(+)$ of 100 $\mathrm{ng} / \mathrm{ml}$ LPS. COX activity was assessed as described in Methods (-LPS, open bars; +LPS, hatched bars), and expressed in nanograms of $\mathrm{PGE}_{2}$ per microgram of total cell protein per well (top pan$e l s)$. Crude lysate protein $(20 \mu \mathrm{g})$ was subjected to immunoblot analysis for COX-2 protein as described in Methods (middle panels), and RT-PCR (35 cycles) analysis of COX-2 mRNA expression was performed as described in Methods (bottom panels).

$\mathrm{PGE}_{2}$ synthesis from exogenous AA (but not exogenous $\mathrm{PGH}_{2}$ ) suggest a defect at the level of the COX enzyme itself. (c) Unlike F-nl, F-IPF were incapable of increasing COX activity after pretreatment with the agonists LPS, PMA, and IL- $1 \beta$. $(d)$ This inability to augment COX metabolic activity correlated with a failure to increase steady-state levels of COX-2 protein and mRNA. (e) Finally, a significant inverse correlation was observed between the $\mathrm{PGE}_{2}$ synthetic capacity of F-IPF and semiquantitative fibrosis scores of lung tissue from which these F-IPF were obtained.

Several methodological features of our study deserve comment. First, cells from three separate lung segments were pooled to obtain the F-IPF used. In the interstitial lung diseases, the degrees of pulmonary inflammation and fibrosis are well known to be heterogeneous in distribution (1). Although pooling cells

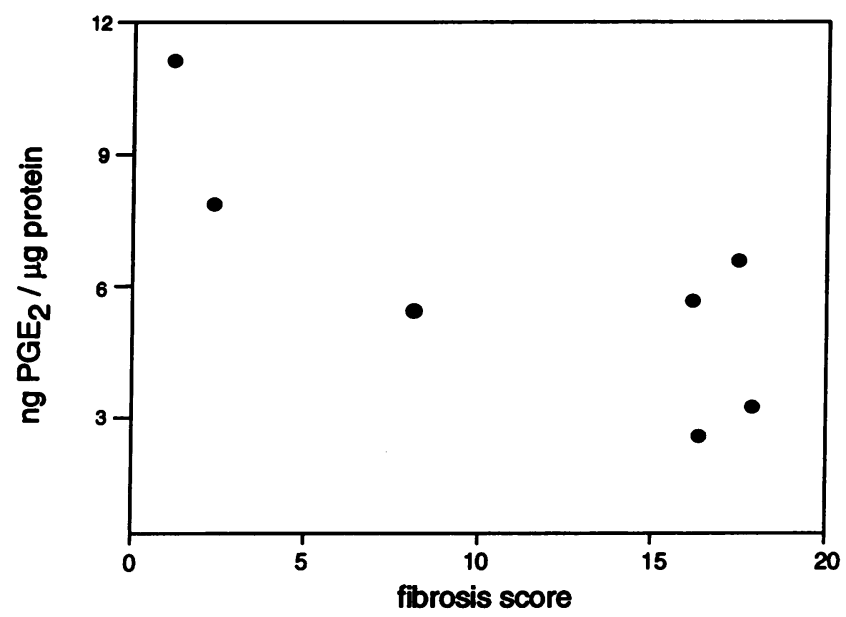

Figure 8 . Correlation between COX activity and fibrosis score. Mean pathologic scores from three biopsy specimens are plotted against COX activity (expressed as nanograms of $\mathrm{PGE}_{2}$ per microgram of protein) in the LPS-stimulated state for each of seven IPF patients. The relationship between $\mathrm{PGE}_{2}$ synthetic capacity and fibrosis is described by the equation $y=9920.8-362.83 x ; r=0.804$. from different regions minimizes the possibility of sampling errors, it also averages out cellular heterogeneity, thereby tending to underestimate the magnitude of abnormalities in the most severely affected areas. Second, because alterations in eicosanoid profiles have been reported to accompany serial passage of fibroblasts (32), we chose to study cells at the fifth passage, reasoning that this was a sufficient passage number to ensure purity, but not so great that differences present in vivo might be lost. Nonetheless, the differences in maximal COX activity between F-nl and F-IPF that we observed have persisted through the 12th passage ( $n=2$ for both cell populations; data not shown). Third, because both the proliferative state and the serum itself can influence PG synthesis and COX activity, we studied quiescent cells at various time points up to $72 \mathrm{~h}$ after removal of serum. The defects in COX activity in F-IPF were observed at all time points.

We initially observed that constitutive $\mathrm{PGE}_{2}$ accumulation in F-IPF was 6.5-fold lower than that in F-nl when cells were studied at $16 \mathrm{~h}$ in culture. We therefore performed HPLC analysis to determine whether there were any differences in the eicosanoid profiles between the two cell types that would account for this finding. A previous report indicated that human skin fibroblasts failed to synthesize 5-lipoxygenase metabolites of AA (33). However, since leukotrienes have the capacity to stimulate fibroblast proliferation and collagen synthesis (34), it was nevertheless of interest to determine whether these metabolites were synthesized by F-IPF. In fact, HPLC analysis detected no lipoxygenase products elaborated by fibroblasts from either patient group. Rather, in both F-IPF and F-nl the major products observed were free $\mathrm{AA}$ and $\mathrm{PGE}_{2}$. What was striking was the markedly reduced capacity of F-IPF to metabolize the released $\mathrm{AA}$ to $\mathrm{PGE}_{2}$, as compared with F-nl. Although we did not compare the two populations for their quantitative capacities to release AA, HPLC analysis of prelabeled cells clearly indicated that F-IPF were capable of releasing free fatty acid,

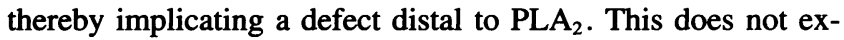
clude a possible concomitant reduction in AA levels that might be available as substrate for COX (i.e., decreased deacylation or increased reacylation) in F-IPF as compared with F-nl. This possibility must be explored in future studies. 
The capacity for $\mathrm{PGH}_{2}$ metabolism was far greater than the cells' capacity for $\mathrm{PGH}_{2}$ formation, suggesting that $\mathrm{COX}$ is the rate-limiting enzyme. Moreover, no differences in PGE isomerase activity were detected between the two cell types in stimulated (data not shown) or basal states. But F-IPF did exhibit 2.5-fold less COX activity than F-nl in the basal state. Despite this, we detected no differences in steady state levels of COX-1 protein and no appreciable COX-2 protein expression in the basal state. Although the mechanism for reduced basal COX activity in F-IPF has not been elucidated in this investigation, several possibilities exist. First, COX-1 enzyme activity in F-IPF may be less per molecule than that in F-nl, reflecting either intrinsic enzyme modifications or differences in modulating factors. Second, the subcellular localization of COX-1 in F-IPF and F-nl might differ, resulting in decreased access of the enzyme in F-IPF to endogenous and exogenous substrate. Third, differences in constitutive expression of COX-2 might exist in the two populations, but may be below the limits of sensitivity of the Western blotting procedure used. Using RTPCR, we did find that whereas COX-1 mRNA levels were similar, COX-2 mRNA levels were indeed lower in F-IPF than in $\mathrm{F}$-nl in the basal state. Identifying the mechanism responsible for this reduction in basal COX activity in F-IPF will require further investigation.

COX activity in F-nl was increased above baseline by the addition of the agonists LPS, PMA, and IL- $1 \beta$ to the culture medium. Evidence that this increase in activity was due to COX2 induction was provided by the observations that the increase in COX activity correlated with COX-2 protein and mRNA expression, that there was no increase in COX-1 expression with agonist stimulation, and that the increases in activity and COX-2 protein expression were both prevented by coincubation with dexamethasone. In contrast to F-nl, F-IPF were refractory to increases in COX activity or COX-2 protein expression by these same stimuli. That refractoriness was observed for three unrelated agonists strongly suggests that the defect resides not at the level of a receptor or signaling mechanism, but at a more distal efferent step in enzyme synthesis. RT-PCR results suggest a failure to increase steady-state mRNA levels upon agonist stimulation. The molecular mechanism underlying this lack of mRNA inducibility remains to be determined, but could reflect enhanced turnover rates for the transcript or reduced transcription rates. This in turn might result from an acquired alteration in the COX-2 promoter, from an inability to alternatively splice a premature transcript (35), or from alterations in the regulation or actions of transcription factors. It will be of great interest in future studies to determine whether other lung cells share this defect in COX-2 inducibility identified in F-IPF.

To our knowledge, this is the first demonstrated association of a lack of inducibility of COX-2 with a human disease. A great deal of attention has been focused on the role of COX-2 in inflammation (36), and the development of selective inhibitors of COX-2 offers the prospect of antiinflammatory efficacy with less gastrointestinal and renal toxicity than current nonselective COX inhibitors (37). However, it is also recognized that certain PGs, including $\mathrm{PGE}_{2}$, can exert potent inhibitory actions on leukocytes $(38,39)$, lymphocytes $(40,41)$, and fibroblasts $(8,9,11,42)$, which participate in the processes of inflammatory injury and repair. Induction of COX-2 by agonists present in the inflammatory milieu of the lung might represent an important mechanism by which fibroblasts can increase their $\mathrm{PGE}_{2}$ synthetic capacity and thereby limit cellular proliferation, collagen synthesis, and production of inflammatory mediators. A defect in this homeostatic process may promote or sustain inflammation and fibrosis in the lung. In this regard, it is intriguing that, despite the small sample size, we observed a significant inverse correlation between the degree of fibrosis and COX activity ( $\mathrm{PGE}_{2}$ synthetic capacity) in fibroblasts isolated from IPF patients. Of note, Borok et al. (43) found significantly less $\mathrm{PGE}_{2}$ in lavage fluid obtained from patients with IPF than in normal subjects. These data therefore highlight the potential detrimental consequences that might result from pharmacologic inhibition of COX-2, at least during the reparative phases of inflammatory injury in the lung. Finally, our observations may have therapeutic ramifications. Augmentation of $\mathrm{PGE}_{2}$ levels in the lung via aerosolization of a stable $\mathrm{PGE}_{2}$ analog (43) or via transfection of the cDNA encoding COX-1 or COX-2 (44) has the potential to reduce fibrosis and ultimately to improve the prognosis for this often devastating disease.

\section{Acknowledgments}

We thank Bing Tan, Robert McNish, Holly Evanoff, and Janet Hampton for technical assistance, Drs. Mark Orringer and Richard Whyte for providing lung tissue specimens, and Drs. William Smith and David DeWitt for kindly providing the COX-1 and COX-2 antisera, respectively.

This work was supported by grants from the National Institutes of Health (RO1-HL47391 and Specialized Center of Research P50HL46487). M. Peters-Golden is the recipient of a Career Investigator Award from the American Lung Association. J. Wilborn is the recipient of a Minority Investigator Research Supplement Award from the National Heart, Lung, and Blood Institute.

\section{References}

1. Panos, R., and T. King. 1991. Idiopathic pulmonary fibrosis. In Immunologically Mediated Pulmonary Diseases. J. P. Lynch III and R. A. DeRemee, editors. J. B. Lippincott, Philadelphia, PA. 1-39.

2. Jordana, M., M. Newhouse, and J. Gauldie. 1987. Alveolar macrophageand peripheral blood monocyte-derived factors modulate proliferation of primary lines of human lung fibroblasts. J. Leukocyte Biol. 42:51-60.

3. Elias, J., B. Freundlich, J. Kern, and J. Rosenbloom. 1990. Cytokine networks in the regulation of inflammation and fibrosis in the lung. Chest. 97:14391445.

4. Gauldie, J., M. Jordana, and G. Cox. 1994. Cytokines and pulmonary fibrosis. Cytokines. 4:931-935.

5. Clark, J., D. Madtes, and G. Raghu. 1993. Effects of platelet-derived growth factor isoform on human lung fibroblast proliferation and collagen gene expression. Exp. Lung Res. 19:327-344.

6. Fine, A., and R. Goldstein. 1986. The effect of transforming growth factor$\beta$ on cell proliferation and collagen formation by lung fibroblasts. J. Biol. Chem. 262:3897-3902.

7. Elias, J., M. Rossman, R. Zurier, and R. Daniele. 1985. Human alveolar macrophage inhibition of lung fibroblast growth: a prostaglandin-dependent process. Am. Rev. Respir. Dis. 131:94-99.

8. Bitterman, P., M. Wewers, S. Rennard, S. Adelberg, and R. Crystal. 1986. Modulation of alveolar macrophage-driven fibroblast proliferation by alternative macrophage mediators. J. Clin. Invest. 77:700-708.

9. Elias, J. 1988. Tumor necrosis factor interacts with interleukin-1 and interferons to inhibit fibroblast proliferation via prostaglandin-dependent and independent mechanisms. Am. Rev. Respir. Dis. 138:652-658.

10. Goldstein, R., and P. Polgar. 1982. The effect and interaction of bradykinin and prostaglandins on protein and collagen production by lung fibroblasts. J. Biol. Chem. 257:8630-8633.

11. Korn, J., P. Halushka, and E. Leroy. 1980. Mononuclear cell modulation of connective tissue function: suppression of fibroblast growth by stimulation of endogenous prostaglandin production. J. Clin. Invest. 65:543-554.

12. Baum, B., S. Moss, R. Breul, and R. Crystal. 1980. Effect of cyclic AMP on the intracellular degradation of newly synthesized collagen. J. Biol. Chem. 255:2843-2847.

13. Levine, L., and I. Alam. 1979. Arachidonic acid metabolism by cells in culture: analyses of culture fluids for cyclooxygenase products by radioimmunoas- 
say before and after separation by high pressure liquid chromatography. Prostaglandins Med. 3:295-304.

14. Korn, J., D. Torres, and E. Downie. 1983. Fibroblast prostaglandin $E_{2}$ synthesis. J. Clin. Invest. 71:1240-1246.

15. Shindo, N., T. Saito, and K. Murayama. 1988. Rapid quantification of 11 prostanoids by combined capillary column gas chromatography and negative ion chemical ionization mass spectrometry: application to prostanoids released from normal human embryonic lung fibroblasts WI38 in a culture medium. Biomed. Environ. Mass. Spec. 15:25-32.

16. Smith, W., and L. Marnett. 1991. Prostaglandin endoperoxide synthase: structure and catalysis. Biochem. Biophys. Acta. 1083:1-17.

17. O'Neill, G., and A. Ford-Hutchinson. 1993. Expression of mRNA for cyclooxygenase-1 and cyclooxygenase- 2 in human tissues. FEBS (Fed Eur. Biochem. Soc.) Lett. 330:156-160.

18. Fu, J.-Y., J. L. Masferrer, K. Seibert, A. Raz, and P. Needleman. 1990 The induction and suppression of prostaglandin $\mathrm{H}_{2}$ synthase (cyclooxygenase) in human monocytes. J. Biol. Chem. 265:16737-16740.

19. Jones, D., P. Carlton, T. McIntyre, G. Zimmerman, and S. Prescott. 1993 Molecular cloning of human prostaglandin endoperoxide synthase type 2 and demonstration of expression in response to cytokines. J. Biol. Chem. 268:90499054.

20. Masferrer, J., K. Siebert, B. Zweifel, and P. Needleman. 1992. Endogenous glucocorticoids regulate an inducible cyclooxygenase enzyme. Proc. Natl. Acad. Sci. USA. 89:3917-3921.

21. Kujubu, D., S. Reddy, B. Fletcher, and H. Herschman. 1993. Expression of the protein product of the prostaglandin synthase-2/TIS10 gene in mitogenstimulated Swiss 3T3 cells. J. Biol. Chem. 268:5425-5430.

22. Watters, L., T. King, M. Schwarz, J. Waldron, R. Stanford, and M. Reuben 1986. A clinical, radiographic, and physiologic scoring system for the longitudinal assessment of patients with idiopathic pulmonary fibrosis. Am. Rev. Respir. Dis. 133:97-103.

23. Rolfe, M., S. Kunkel, T. Standiford, S. Chensue, R. Allen, H. Evanoff, S. Phan, and R. Strieter. 1992. Pulmonary fibroblast expression of interleukin-8: a model for alveolar macrophage-derived cytokine networking. Am. J. Respir. Cell. Mol. Biol. 5:493-501.

24. Peters-Golden, M., R. W. McNish, R. Hyzy, C. Shelly, and G. B. Toews. 1990. Alterations in the pattern of arachidonate metabolism accompany rat macrophage differentiation in the lung. J. Immunol. 144:263-270.

25. Bradford, M. 1976. A rapid and sensitive method for the quantitation of microgram quantities of protein utilizing the principle of protein-dye binding. Anal. Biochem. 72:248-254.

26. Laemmli, U. 1970. Cleavage of structural proteins during the assembly of the head of bacteriophage T4. Nature (Lond.). 227:680-685.

27. Meade, E., W. Smith, and D. DeWitt. 1993. Differential inhibition of prostaglandin endoperoxide synthase (cyclooxygenase) isozymes by aspirin and other non-steroidal anti-inflammatory drugs. J. Biol. Chem. 268:6610-6614

28. Smith, W., and T. Rollins. 1982. Characteristics of rabbit anti-PGH synthase antibodies and use in immunochemistry. Methods Enzymol. 86:213-222.
29. O'Sullivan, M., E. Huggins, Jr., E. Meade, D. DeWitt, and C. McCall. 1992. Lipopolysaccharide induces prostaglandin $\mathrm{H}$ synthase-2 in alveolar macrophages. Biochem. Biophys. Res. Commun. 187:1123-1127.

30. Hong, S., G. Patton, and D. Deykin. 1979. Arachidonic acid levels in cellular lipids determine the amount of prostaglandins synthesized during cell growth in tissue culture. Prostaglandins. 17:53-59.

31. O'Banion, M., H. Sadowski, V. Winn, and D. Young. 1991. A serumand glucocorticoid-regulated 4-kilobase mRNA encodes a cyclooxygenase-related protein. J. Biol. Chem. 206:23261-23267.

32. Polgar, P., and L. Taylor. 1980. Alterations in prostaglandin synthesis during senescence of human lung fibroblasts. Mech. Ageing Dev. 12:305-313.

33. Bernd, M., R. Ludwig, E. Zenzmaier, H. Gleispach, and H. Esterbauer. 1984. Characterization of lipoxygenase metabolites of arachidonic acid in cultured human skin fibroblasts. Biochim. Biophys. Acta. 795:151-164.

34. Baud, L., J. Perez, M. Denis, and R. Ardaillou. 1987. Modulation of fibroblast proliferation by sulfidopeptide leukotrienes: effect of indomethacin. $J$. Immunol. 138:1190-1195.

35. Diaz, A., A. Reginato, and S. Jimenez. 1992. Alternative splicing of human prostaglandin $\mathrm{G} / \mathrm{H}$ synthase $\mathrm{mRNA}$ and evidence of differential regulation of the resulting transcripts by transforming growth factor $\beta_{1}$, interleukin $1 \beta$, and tumor necrosis factor $\alpha$. J. Biol. Chem. 267:10816-10822.

36. Vane, J. 1994. Towards a better aspirin. Nature (Lond.). 367:215-216.

37. Masferrer, J., B. Zweifel, P. Manning, S. Hauser, K. Leahy, W. Smith, P. Isakson, and K. Seibert. 1994. Selective inhibition of inducible cyclooxygenase2 in vivo is antiinflammatory and nonulcerogenic. Proc. Natl. Acad. Sci. USA. 91:3228-3236.

38. Ham, E., D. Soderman, M. Zanetti, H. Dougherty, E. McCauley, and F. Kuehl, Jr. 1983. Inhibition by prostaglandins of leukotriene B4 release from activated neutrophils. Proc. Natl. Acad. Sci. USA. 80:4349-4353.

39. McLeish, K., G. Stelzer, and J. Wallace. 1987. Regulation of oxygen radical release from murine peritoneal macrophages by pharmacologic doses of $\mathrm{PGE}_{2}$. Free Radical Biol. Med. 3:15-20.

40. Oppenheimer-Marks, N., A. Kavanaugh, and P. Lipsky. 1994. Inhibition of the transendothelial migration of human $T$ lymphocytes by prostaglandin $E_{2}$. J. Immunol. 152:5703-5713.

41. Betz, M., and B. Fox. 1991. Prostaglandin $E_{2}$ inhibits production of Th1 lymphokines but not of Th2 lymphokines. J. Immunol. 146:108-113.

42. Goldstein, R., and A. Fine. 1986. Fibrotic reactions in the lung: the activation of the lung fibroblast. Exp. Lung Res. 11:245-261.

43. Borok, Z., A. Gillissen, R. Buhl, R. Hoyt, R. Hubbard, T. Ozaki, S. Rennard, and R. Crystal. 1991. Augmentation of functional prostaglandin E levels on the respiratory epithelial surface by aerosol administration of prostaglandin E. Am. Rev. Respir. Dis. 144:1080-1084.

44. Conary, J., R. Parker, B. Christman, R. Faulks, G. King, B. Meryick, and K. Brigham. 1994. Protection of rabbit lungs from endotoxin injury by in vivo hyperexpression of the prostaglandin $\mathrm{G} / \mathrm{H}$ synthase gene. J. Clin. Invest. 93:1834-1840. 